\title{
Single-Agent Irinotecan for Recurrent/Metastatic Colorectal Cancer: A Retrospective Analysis
}

\author{
Ulus A. Sanli ${ }^{a}$ Bulent Karabulut $^{a}$ Ruchan Uslu ${ }^{a}$ Mustafa Korkut $^{\mathrm{b}}$ \\ Erdem Goker ${ }^{\mathrm{a}}$ \\ ${ }^{a}$ Department of Internal Medicine, Division of Medical Oncology, and ${ }^{b}$ Department of General Surgery, \\ Division of Proctology, Ege University School of Medicine, Bornova/lzmir, Turkey
}

\section{Key Words}

Irinotecan - Colorectal carcinoma, survival ·

Prognostic factors

\begin{abstract}
Objective: To evaluate the efficacy, toxicity and factors affecting the survival rate of patients treated with irinotecan. Subjects and Methods: Data from the medical records of 74 patients who had recurrent/metastatic colorectal cancer treated with single-agent irinotecan were analyzed. Results: The mean age for all the patients was 56 years (range $19-77)$. Forty-one (55\%) and 33 (45\%) patients had recurrent and/or metastatic colon cancer, respectively. All the patients were treated with irinotecan $350 \mathrm{mg} / \mathrm{m}^{2}$ every 21 days. Grade 3-4 emesis, grade 34 diarrhea, grade 3-4 neutropenia and severe early cholinergic events developed in $7,15,7$ and $1.3 \%$ of patients, respectively. One patient died due to acute renal failure. The overall response rate was $14 \%$ (complete response $5 \%$, partial response $9 \%$ ); $61 \%$ had stable response while another $25 \%$ had progressive disease. Patients with multiple metastatic foci, patients $\leq 50$ years of age and patients with peritonitis carcinomatosa were shown to have worse outcomes than others. The median duration of response was 16.7 months. The median progression-
\end{abstract}

free survival and overall survival were 4 and 14 months, respectively. Conclusion: The data show that irinotecan was useful in the treatment of recurrent/metastatic colorectal cancer with acceptable toxicity.

Copyright (C) 2006 S. Karger AG, Basel

\section{Introduction}

Colorectal cancer is the second leading cause of death due to cancer; in the United States about 57,000 deaths were predicted in 2003 [1]. Early diagnosis of colorectal cancer and developments in therapy have led to a significant increase in the survival time. For the last 40 years, 5-fluorouracil (5-FU) has been the first-line treatment option for advanced colorectal cancer. The response rate to 5-FU treatment has been $11 \%$, increasing up to $23 \%$ when folinic acid (FA) is added [2]. Continuous intravenous infusion has been shown to be superior to bolus treatment [3-5]. Until the 1990s, the 5-FU/FA combination was the standard treatment approach for advanced colorectal cancer; however, in the last decade, irinotecan, capecitabine, and oxaliplatin have become the major chemotherapeutic agents. Current studies are focused on targeted therapies.

\section{KARGER}

Fax +4161306 1234

E-Mail karger@karger.ch

www.karger.com
(C) 2006 S. Karger AG, Basel

1011-7571/06/0154-0288\$23.50/0

Accessible online at:

www.karger.com/mpp
Ulus Ali Sanli, MD, Ass. Prof.

Department of Medical Oncology

Ege University School of Medicine

TR-35100 Bornova/Izmir (Turkey)

Tel./Fax +90 23237473 21, E-Mail ulusali@med.ege.edu.tr 
Irinotecan acts by inhibiting topoisomerase I. Its efficacy in the treatment of colorectal cancer has been shown to improve survival in patients resistant to 5-FU therapy, receiving supportive treatment for advanced colorectal cancer or 5-FU infusion therapy [6-8]. Equally, a combination treatment of irinotecan/5-FU/FA has been shown to be more effective than 5-FU/FA $[9,10]$ with regard to progression-free survival (PFS) and overall survival (OS).

In patients with 5-FU-refractory colorectal cancer, phase II trials of irinotecan treatment demonstrated objective response rates of $12-15 \%$ and median survivals of 8-9 months [11, 12]. Diarrhea and neutropenia were the principal adverse events. Subsequently, two phase III trials demonstrated statistically significant survival advantages for patients randomly assigned to irinotecan, compared with patients given either best supportive care or second-line infusional 5-FU [7, 8]. In both trials, irinotecan was delivered on a 3-week schedule. Although phase II efficacy and safety results with the weekly and 3-week regimens seemed to be equivalent, no formal comparison of these regimens has been performed. Fuchs et al. [13] reported a randomized phase III study on two different irinotecan second-line dosing regimens in metastatic colorectal cancer. These authors concluded that irinotecan schedules of weekly and 3-week intervals demonstrated similar efficacy and quality of life in patients with FUrefractory metastatic colorectal cancer. The regimen of once every 3 weeks was associated with a significantly lower incidence of severe diarrhea.

In this study, we aimed to investigate the response rates, toxicity, PFS, OS and factors affecting PFS and OS in patients who have advanced stage colorectal cancer treated with irinotecan as a first- or second-line treatment.

\section{Subjects and Methods}

\section{Patient Eligibility}

Inclusion criteria for the analysis of patients with histologically proven adenocarcinoma of the colon or rectum were age 1875 years, Eastern Cooperative Oncology Group performance status of $0-2$, absolute neutrophil count $\geq 1,500$ cells $/ \mu \mathrm{l}$, hemoglobin $\geq 8 \mathrm{~g} / \mathrm{dl}$, platelets $\geq 100,000 / \mu \mathrm{l}$, bilirubin $\leq 1.5 \mathrm{mg} / \mathrm{dl}$, creatinine $\leq 2.0 \mathrm{mg} / \mathrm{dl}$ and ALT, AST or alkaline phosphatase levels $\leq 1.5$ times the upper limit of normal in the absence of bone or liver metastasis, or $\leq 2.5$ times the upper limit of normal in the presence of liver or bone metastasis, respectively. The patients all had measurable disease, all had physical examination, chest X-ray, abdominal ultrasound or computerized tomographic scan of metastatic sites; bone scan was performed when symptoms were suggestive of skeletal involvement or prior metastatic bone disease.

\section{Response Evaluation}

Assessment of toxicity (including serum chemistries and blood counts) was done every 21 days. All toxicities were evaluated and scored according to the World Health Organization scale. Radiological assessment of the tumor was repeated every 3 cycles of therapy. Complete response was defined as disappearance of all clinical and radiological evidence; partial response as $50 \%$ or greater decrease in the sum of the products of diameters of all index lesions persisting for at least one cycle of therapy. Stable disease was defined as no change in tumor size or change that was too small to qualify as progressive disease and partial-response progressive disease as either an increase of $\geq 25 \%$ in the sum of the products of diameters of any index lesions, 50\% increase in the estimated size of nonmeasurable lesions, or appearance of any unequivocally new lesion. PFS was calculated from the date of the start of the first cycle to the date of the event occurrence.

\section{Treatment Plan}

Irinotecan $350 \mathrm{mg} / \mathrm{m}^{2}$ was given every 3 weeks according to treatment protocol. Treatment was stopped if the disease progressed, the patient developed unacceptable toxic effects, or consent was withdrawn. Irinotecan was administered according to the guidelines used for irinotecan monotherapy, including recommendations for the use of concurrent antiemetics, atropine, and loperamide. Doses were lowered by $20 \%$ if severe toxic effects occurred and starting doses were reduced to $300 \mathrm{mg} / \mathrm{m}^{2}$ in patients older than 70 years having had prior radiotherapy. At the end of the treatment period, patients were followed up for progression every 3 months. Further cancer treatment was also recorded.

\section{Statistical Analysis}

The PFS and OS curves were plotted according to Kaplan-Meier estimate. Statistical analyses were carried out with log-rank tests. Patients were subgrouped for further analyses into colon vs. rectal cancer, monofocal vs. multifocal metastasis, $\leq 50$ vs. $>50$ years and with or without peritonitis carcinomatosa. SPSS (Statistical Package for Social Sciences) version 10.0 was used for the statistical analysis; $\mathrm{p}$ values are significant if less than 0.05 .

\section{Results}

Of the 74 patients, $38(52 \%)$ suffered from metastatic colon cancer, 29 (39\%) metastatic rectum cancer, 3 (4\%) recurrent local colon cancer and $4(5 \%)$ recurrent local rectum cancer. Liver metastasis was present in 44 patients (59\%), while 29 (39\%) had lung metastasis, 13 (18\%) peritonitis carcinomatosa, $1(1.3 \%)$ lymph node metastasis and $1(1.3 \%)$ bone metastasis. Single metastasis was present in $50(68 \%)$ patients while $24(32 \%)$ had multiple metastasis. General characteristics of the patient population are presented in table 1. Forty-six (62\%) were male and $28(38 \%)$ female with a mean age of 56 years (19-77); 53 (72\%) patients received first-line treatment and $21(28 \%)$ second-line treatment. The mean WHO performance status was $1(0-2)$. A total of 501 cycles 


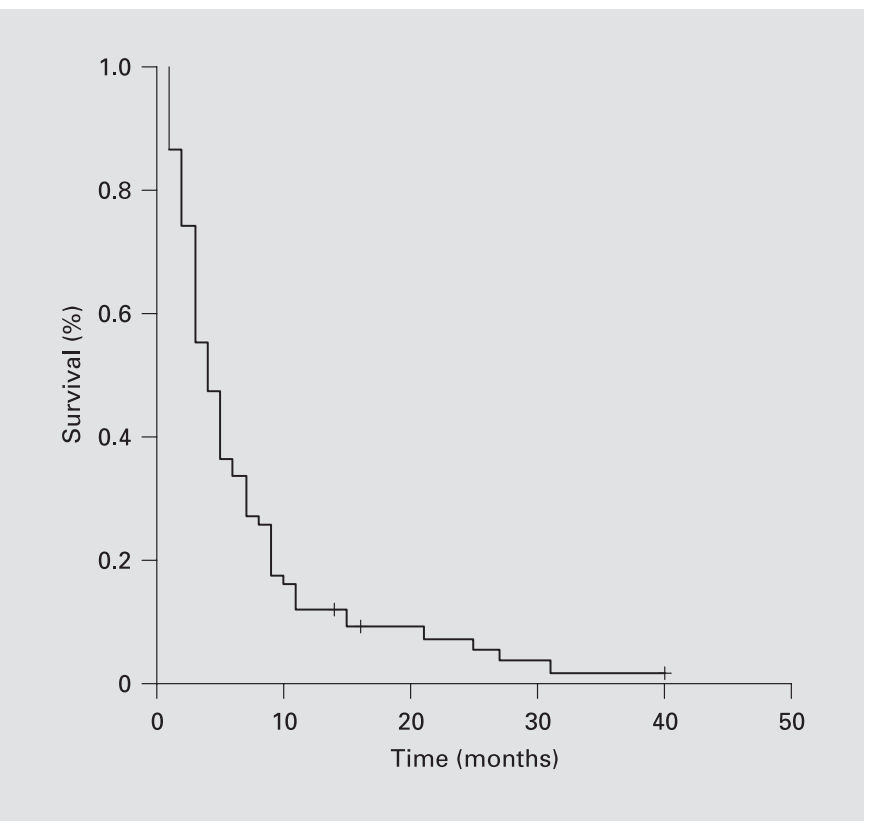

Fig. 1. Progression-free survival.

Table 1. Patient characteristics

\begin{tabular}{|c|c|c|}
\hline & Patients & $\%$ \\
\hline \multicolumn{3}{|l|}{ Sex } \\
\hline Male & 46 & 62 \\
\hline Female & 28 & 38 \\
\hline Age, years & $56(19-77)$ & \\
\hline WHO Performance Status & $1(0-2)$ & \\
\hline \multicolumn{3}{|l|}{ Primary disease } \\
\hline Metastatic colon cancer & 38 & 52 \\
\hline Metastatic rectum cancer & 29 & 39 \\
\hline Recurrent colon cancer & 3 & 4 \\
\hline Recurrent rectum cancer & 4 & 5 \\
\hline \multicolumn{3}{|l|}{ Tumor involvement } \\
\hline Liver metastasis & 44 & 59 \\
\hline Pulmonary metastasis & 29 & 39 \\
\hline Local recurrence & 11 & 15 \\
\hline Peritonitis carcinomatosa & 13 & 19 \\
\hline Lymph node metastasis & 1 & 1.3 \\
\hline Bone metastasis & 1 & 1.3 \\
\hline \multicolumn{3}{|l|}{ Metastatic focus } \\
\hline Monofocal & 50 & 68 \\
\hline Multiple foci & 24 & 32 \\
\hline \multicolumn{3}{|l|}{ Chemotherapy } \\
\hline First-line treatment & 53 & 72 \\
\hline Second-line treatment & 21 & 28 \\
\hline
\end{tabular}

Number of patients is given unless otherwise indicated.

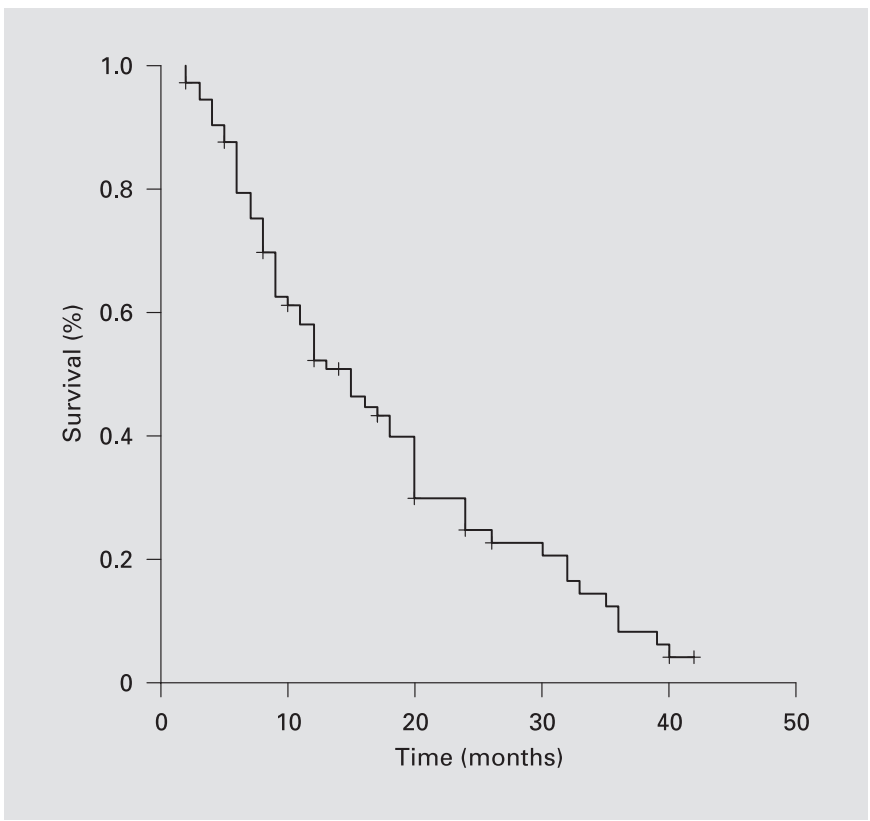

Fig. 2. Overall survival.

(mean 6.8 cycles with a range of $1-36$ cycles) of irinotecan treatment was administered. In patients with grade 3-4 toxicity, emesis occurred in $5(7 \%)$ patients, diarrhea in $11(15 \%)$, neutropenia in $5(7 \%)$ and severe early cholinergic symptoms in $1(1.3 \%)$. One patient died due to acute renal failure.

The overall response rate was $14 \%$ (complete response $5 \%$ and partial response $9 \%$ ). Sixty-two percent (62\%) had a stable disease, whereas progressive disease was seen in $24 \%$ of patients (table 2). The median duration of response was 16.7 months; median PFS was 4 months (fig. 1) and median OS 14 months (fig. 2). Patients with multifocal metastasis, peritonitis carcinomatosa or age $\leq 50$ years did not respond as well as others, but this was not statistically significant. Liver metastasis had no adverse effects on results. Median PFS and OS time for patient subgroups are presented in table 3.

\section{Discussion}

Irinotecan has an important role in the treatment of colorectal cancer and has been proven to be effective in the treatment of metastatic colorectal cancer [6-10]. Irinotecan acts by inhibiting topoisomerase I through in vivo conversion to $\mathrm{SN}-38$ [14-16]. In this study, the overall response rate $(14 \%)$ and stabilization rate $(61 \%)$ in 
Table 2. Response rates according to subgroups

\begin{tabular}{llllr}
\hline & Complete & Partial & Stable & Progression \\
\hline First-line $(\mathrm{n}=53)$ & $3(6)$ & $4(8)$ & $33(62)$ & $13(24)$ \\
Second-line $(\mathrm{n}=21)$ & $1(5)$ & $2(10)$ & $12(57)$ & $6(28)$ \\
Monofocal metastasis $(\mathrm{n}=50)$ & $4(8)$ & $5(10)$ & $26(52)$ & $15(30)$ \\
Multiple metastasis $(\mathrm{n}=24)$ & $0(0)$ & $1(4)$ & $19(79)$ & $4(17)$ \\
Monofocus (n = 24) & & & & \\
$\quad($ excluding liver or peritoneum) & $1(4)$ & $1(4)$ & $15(63)$ & $7(29)$ \\
Liver metastasis $(\mathrm{n}=44)$ & $2(5)$ & $5(11)$ & $28(64)$ & $9(20)$ \\
Peritonitis carcinomatosa (n=13) & $1(8)$ & $1(8)$ & $7(54)$ & $4(30)$ \\
Rectum $(\mathrm{n}=33)$ & $1(3)$ & $3(9)$ & $21(64)$ & $8(24)$ \\
Colon (n= $=41)$ & $3(7)$ & $3(7)$ & $24(59)$ & $11(27)$ \\
\hline
\end{tabular}

Figures in parentheses are percentages.
Table 3. Median PFS and OS for patient subgroups

\begin{tabular}{lllll}
\hline & $\begin{array}{l}\text { PFS } \\
\text { months }\end{array}$ & p & $\begin{array}{l}\text { OS } \\
\text { months }\end{array}$ & $\mathrm{p}$ \\
\hline First-line & 4 & 0.99 & 13 & 0.52 \\
Second-line & 4 & & 15 & 0.29 \\
\hline Monofocal metastasis & 4 & 0.6 & 15 & 13 \\
Multifocal metastasis & 4 & & 15 & 0.2 \\
\hline Focus excluding peritoneum & 5 & 0.2 & 12 & 0.4 \\
Peritonitis carcinomatosa & 4 & 0.82 & 12 & 17 \\
\hline Rectal cancer & 4 & & 14 & 0.05 \\
Colon cancer & 5 & 0.24 & 16 & \\
\hline$\leq 50$ years & 4 & &
\end{tabular}

patients receiving irinotecan as first-line treatment and overall response rate (15\%) and stable disease rate $(57 \%)$ in patients receiving irinotecan as second-line treatment are similar to reported values $(18-39 \%)$ for first-line [9, 10] and second-line treatment (10.4-22.0\%) [17-21]. Clinical studies have shown that diarrhea and myelosuppression are the most important toxicities of irinotecan. Uridine diphosphate glucuronyl transferase 1A1 (UGT1A1), an enzyme in hepatic glucuronidation of SN38 , is the most important factor determining toxicity and it shows genetic polymorphism [22, 23]. Prevalence of diarrhea has decreased with concomitant use of high-dose loperamide leading to increased safety of the drug.

In our study, grade 3-4 toxicity was seen in about 30\% of patients. Therefore, close follow-up of patients for toxicities and dose adjustments is necessary. Due to the high rates of early mortality related to weekly IFL treatment, oncologists decreased starting doses by $20 \%$ [24].

Analysis of previous studies revealed that parameters such as performance status, weight loss, alkaline phosphatase level, bilirubin level, leukocyte count, hemoglobin level, number of organs with metastatic involvement and liver involvement affected response rates in irinotecan therapy $[25,26]$. Negative prognostic factors were investigated in this patient group. As a result, patients with multiple metastasis, patients $\leq 50$ years of age and patients with peritonitis carcinomatosa had worse outcomes. In a meta-analysis of patients with metastatic colorectal cancer treated with 5-FU, an increase in the number of metastatic foci and presence of peritonitis carcinomatosa are shown to worsen the prognosis [27]. Liver metastasis did not adversely affect the results. Metastasectomy after irinotecan treatment and longer PFS in some patients with liver metastasis (3 patients) are thought to improve results.

In recent years, significant improvements in the treatment of colorectal cancer occurred with the use of chemotherapeutic agents such as irinotecan, oxaliplatin and capecitabine. In recent studies, irinotecan has been used in combination with oxaliplatin [28], cetuximab [29] and COX-2 inhibitors [30] to increase its efficacy. Results of these studies will improve the response rates and quality of life scores of patients with metastatic colorectal cancer.

\section{Conclusion}

In this study, the data showed that irinotecan, as a single agent, is effective in metastatic colorectal cancer treatment with manageable toxicities. 


\section{References}

1 Cancer Facts and Figures, 2003. American Cancer Society, 2003.

2 Modulation of fluorouracil by leucovorin in patients with advanced colorectal cancer: evidence in terms of response rate. Advanced Colorectal Cancer Meta Analysis Project. J Clin Oncol 1992;10:896-903.

>3 de Gramont A, Bosset JF, Milan C, Rougier P, Bouche O, Etienne PL, Morvan F, Louvet C, Guillot T, Francois E, Bedenne L: Randomized trial comparing monthly low-dose leucovorin and fluorouracil bolus with bimonthly high-dose leucovorin and fluorouracil bolus plus continuous infusion for advanced colorectal cancer: a French Intergroup Study. J Clin Oncol 1997; 15:808-815.

4 Lokich JJ, Ahlgren JD, Gullo JJ, Philips JA, Fryer JG: A prospective randomised comparison of continuous infusion fluorouracil with a conventional bolus schedule in metastatic colorectal carcinoma: a Mid-Atlantic Oncology Program Study. J Clin Oncol 1989; 7:425432.

$>5$ The Meta-Analysis Group in Cancer: Efficacy of intravenous continuous infusion of fluorouracil compared with bolus administration in advanced colorectal cancer. J Clin Oncol 1998; 16:301-308

-6 Rothenberg ML, Kuhn JG, Burris HA 3rd, Nelson J, Eckardt JR, Tristan-Morales M, Hilsenbeck SG, Weiss GR, Smith LS, Rodriguez GI, Rock MK, Von Hoff DD: Phase I and pharmacokinetic trial of weekly CPT-11. J Clin Oncol 1993;11:2194-2204.

-7 Cunningham D, Pyrhonen S, James RD, Punt CJ, Hickish TF, Heikkila R, Johannesen TB, Starkhammar H, Topham CA, Awad L, Jacques C, Herait P: Randomised trial of irinotecan plus supportive care versus supportive care alone after fluorouracil failure for patients with metastatic colorectal cancer. Lancet 1998 ; 352:1413-1418

$>8$ Rougier P, Van Cutsem E, Bajetta E, Niederle N, Possinger K, Labianca R, Navarro M, Morant R, Bleiberg H, Wils J, Awad L, Herait P, Jacques C: Randomized trial of irinotecan versus fluorouracil by continuous infusion after fluorouracil failure in patients with metastatic colorectal cancer. Lancet 1998;352:14071412.

-9 Saltz LB, Cox JV, Blanke C, Rosen LS, Fehrenbacher L, Moore MJ, Maroun JA, Ackland SP Locker PK, Pirotta N, Elfring GL, Miller LL: Irinotecan plus fluorouracil and leucovorin for metastatic colorectal cancer. Irinotecan Study Group. N Engl J Med 2000;343:905-914.

$>10$ Douillard JY, Cunningham D, Roth AD, Navarro M, James RD, Karasek P, Jandik P, Iveson T, Carmichael J, Alakl M, Gruia G, Awad L, Rougier P: Irinotecan combined with fluorouracil compared with fluorouracil alone as first-line treatment for metastatic colorectal cancer: a multicentre randomized trial. Lancet 2000;355:1041-1047.
$>11$ Pitot HC, Wender DB, O'Connell MJ, Schroeder G, Goldberg RM, Rubin J, Mailliard JA, Knost JA, Ghosh C, Kirschling RJ, Levitt R, Windschitl HE: Phase II trial of irinotecan in patients with metastatic colorectal cancer. J Clin Oncol 1997;15:2910-2919.

-12 Rothenberg ML, Cox JV, DeVore RF, Hainsworth JD, Pazdur R, Rivkin SE, Macdonald JS, Geyer CE Jr, Sandbach J, Wolf DL, Mohrland JS, Elfring GL, Miller LL, Von Hoff DD A multicenter, phase II trial of weekly irinotecan (CPT-11) in patients with previously treated colorectal cancer. Cancer 1999;85:786795.

13 Fuchs CS, Moore MR, Harker G, Villa L, Rinaldi D, Hecht JR: Phase III comparison of two irinotecan dosing regimens in second-line therapy of metastatic colorectal cancer. J Clin Oncol 2003;21:807-814

14 Kaneda N, Nagata H, Furuta T, Yokokura T: Metabolism and pharmacokinetics of the camptothecin analogue CPT-11 in the mouse. Cancer Res 1990;50:1715-1720.

15 Kawato Y, Aonuma M, Hirota Y, Kuga H, Sato K: Intracellular roles of SN-38, a metabolite of the camptothecin derivative CPT-11, in the anti-tumor effect of CPT-11. Cancer Res 1991;51:4187-4191.

16 Rivory LP, Riou JF, Haaz MC, Sable S, Vuilhorgne M, Commercon A, Pond SM, Robert J: Identification and properties of a major plasma metabolite of irinotecan (CPT-11) isolated from the plasma of patients. Cancer Res 1996; 56:3689-3694.

17 Shimada Y, Yoshino M, Wakui A, Nakao I, Futatsuki K, Sakata Y, Kambe M, Taguchi T, Ogawa N: Phase II study of CPT-11, a new camptothecin derivative, in metastatic colorectal cancer. J Clin Oncol 1993;11:909-913.

18 Shimada Y, Rougier P, Pitot H: Efficacy of CPT-11 (irinotecan) as a single agent in metastatic colorectal cancer. Eur J Cancer 1996 32A(suppl 3):13S-17S

19 Rothenberg, ML, Eckardt JR, Kuhn JG, Burris HA 3rd, Nelson J, Hilsenbeck SG, Rodriguez GI, Thurman AM, Smith LS, Eckhardt SG, Weiss GR, Elfring GL, Rinaldi DA, Schaaf LJ, Von Hoff DD: Phase II trial of irinotecan in patients with progressive or rapidly recurrent colorectal cancer. J Clin Oncol 1996;14:11281135 .

20 Rougier P, Bugat R, Douillard JY, Culine S, Suc E, Brunet P, Becouarn Y, Ychou M, Marty M, Extra JM, Bonneterre J, Adenis A, Seitz JF, Ganem G, Namer M, Conroy T, Negrier S, Merrouche Y, Burki F, Mousseau M, Herait P, Mahjoubi M: Phase II study of irinotecan in the treatment of advanced colorectal cancer in chemotherapy-naïve patients and patients pretreated with fluorouracil-based chemotherapy. J Clin Oncol 1997; 15:251-260.
21 Van Cutsem E, Cunningham D, Ten Bokkel Huinink WW, Punt CJ, Alexopoulos CG, Dirix L, Symann M, Blijham GH, Cholet P, Fillet G, Van Groeningen C, Vannetzel JM, Levi F, Panagos G, Unger C, Wils J, Cote C, Blanc C, Herait P, Bleiberg H: Clinical activity and benefit of irinotecan (CPT-11) in patients with colorectal cancer truly resistant to 5-fluorouracil (5-FU). Eur J Cancer 1999;35:54-59.

22 Ando Y, Saka H, Ando M, Sawa T, Muro K, Ueoka H, Yokoyama A, Saitoh S, Shimokata K, Hasegawa Y: Polymorphism of UDP-glucuronosyltransferase gene and irinotecan toxicity: a pharmacogenetic analysis. Cancer Res 2000;60:6921-6926.

23 Iyer L, Das S, Janisch L, Wen M, Ramirez J, Harrison T, Fleming GF, Vokes EE, Schilsky RL, Ratain MJ: UGTIA1 28 polymorphism as a determinant of irinotecan disposition and

toxicity. Pharmacogenomics J 2002;2:43-47.
24 Sargent DJ, Niedzwiecki D, O'Connell MJ, Schilsky RL: Recommendation for caution with irinotecan, fluorouracil, and leucovorin for colorectal cancer. N Engl J Med 2001;345: 144-145.

25 Rothenberg ML, Blanke CD: Topoisomerase I inhibitors in the treatment of colorectal cancer. Semin Oncol 1999;26:632-639.

26 Vanhoefer U, Harstrick A, Achterrath W, Cao $\mathrm{S}$, Seeber S, Rustum YM: Irinotecan in the treatment of colorectal cancer: clinical overview. J Clin Oncol 2001;19:1501-1518.

-27 Kohne CH, Cunningham D, Di CF, Glimelius B, Blijham G, Aranda E, Scheithauer W, Rougier P, Palmer M, Wils J, Baron B, Pignatti F, Schoffski P, Micheel S, Hecker H: Clinical determinants of survival in patients with 5fluorouracil-based treatment for metastatic colorectal cancer: results of a multivariate analysis of 3825 patients. Ann Oncol 2002;13: 308-317.

28 Goetz MP, Erlichman C, Windebank AJ, Reid JM, Sloan JA, Atherton P, Adjei AA, Rubin J, Pitot H, Galanis E, Ames MM, Goldberg RM: Phase I and pharmacokinetic study of two different schedules of oxaliplatin, irinotecan, fluorouracil, and leucovorin in patients with solid tumors. J Clin Oncol 2003;21:3716-3717.

29 Saltz LB, Rubin M, Tchekmeydian HH, Waksal H, Needle M, LoBublio A: Cetuximab (IMC-225) plus irinotecan is active in CPT-11 refractory colorectal that expresses epidermal growth factor receptor (abstract 7). Proc Am Soc Clin Oncol 2001;20:3a

30 Blanke CD, Benson AB, Dragovich T, Lenz H, Haller D, Robles C, Buchbinder A: A phase II trial of celecoxip (CX), irinotecan (I), 5-fluorouracil (5FU), and leucovorin (LCV) in patients (pts) with unresectable or metastatic colorectal cancer (CRC) (abstract 505). Proc Am Soc Clin Oncol 2002;21:127a. 